\title{
Detección molecular del virus de la leucosis bovina: un estudio por conglomerados en Colombia
}

\section{Molecular detection of bovine leukemia virus: A study in Colombia cluster}

Fecha de recepción: 17 de abril de 2016

Fecha de aceptación: 15 de junio de 2016
Giovanna Meza-Barreto ${ }^{1}$

Danny Wilson Sanjuanelo-Corredor ${ }^{2}$ Manuel Isaac Gallego-Marín ${ }^{3}$

\section{Resumen}

La leucosis bovina enzoótica (LBE) es ocasionada por un virus de la familia Retroviridae, el virus de la leucosis bovina (VLB), que afecta bovinos de cualquier edad, sexo y raza y genera importantes pérdidas económicas. En Colombia, los pocos estudios moleculares se concentran en ganado de leche; por ello, el presente trabajo se dirigió a detectar el VLB mediante una prueba molecular de PCR en animales destinados a diferentes tipos de explotación ganadera y de diferentes regiones del país, con el propósito de evaluar la relación entre la presencia del VLB en los animales, la ubicación geográfica y el tipo de explotación bovina. De un total de 230 animales, organizados por conglomerados según la región de origen, el 22.6 \% se detectó con el VLB; de estos la región Centro presentó el mayor número de animales infectados $(50.7 \%)$. En cuanto al tipo de producción, el ganado de leche fue el más susceptible a ser infectado por el VLB $(50.7 \%)$. Los resultados indican que existe una significativa relación entre la presencia molecular del virus, la ubicación geográfica de los animales y el tipo de explotación bovina, datos importantes para la planeación de programas de prevención y control de la LBE por los organismos gubernamentales de salud animal.

Palabras clave: bovinos; Leucosis Bovina Enzoótica; PCR.

\begin{abstract}
The Enzootic Bovine Leukemia (EBL) is caused by a virus of the Retroviridae family, the Bovine Leukosis Virus (BLV), affecting cattle of any age, sex, race and generates significant economic losses. The few molecular studies carried out in Colombia, are focus on dairy cattle. For that reason, the present work, was directed to detect VLB by molecular PCR test in cattle, for different farms and regions, in order to evaluate

1 M.Sc. Universidad de Ciencias Aplicadas y Ambientales (Bogotá D.C., Colombia).gmeza@udca.edu.co.

2 Esp. Universidad de Ciencias Aplicadas y Ambientales (Bogotá D.C., Colombia).dsanjuanelo@udca.edu.co.

3 M.Sc. Universidad de Ciencias Aplicadas y Ambientales (Bogotá D.C., Colombia).mgallego@udca.edu.co.
\end{abstract}


the relationship between the presence of VLB in animals, with the geographic location and bovine livestock.

Out of a total 230 clusters animals organized by region of origin, $22.6 \%$ of they were detected infected with VLB; of these, the Centre region had the highest number of infected animals (50.7 \%). As for the production type, dairy cattle were the most likely to be infected by the VLB (50.7\%). Results indicate a significant relationship between the presence of virus, with the geographic location and type of production. These results, are important in order to formulate control and preventives programs by the government agencies of animal health.

Keywords: bovines; Enzootic Bovine Leukosis; livestock; PCR. 


\section{Introducción}

La leucosis bovina enzoótica (LBE) es una enfermedad ocasionada por el Virus de la Leucosis Bovina (VLB), un retrovirus de la familia Retroviridae que afecta bovinos de cualquier edad, sexo y raza (1). En Colombia se registra el $29 \%$ de seroprevalencia en hatos del territorio nacional (2), pero las cifras varían según las regiones del país; en el Nororiente se mencionan datos de entre el $3.9 \%$ y el $14.64 \%$; en la región Andina los datos son del $25 \%$; en la región Caribe, el $14 \%$, y en el piedemonte Llanero, el 15\% (1). Estudios por departamentos muestran el $21 \%$ en Córdoba, el 25 $\%$ en el Valle del Cauca (3), el $19 \%$ en Nariño (4), el $45 \%$ en Cundinamarca, el $73 \%$ en Santander (5) y $15 \%$ de seropositividad en Yopal-Casanare (6). La mayoría de los animales no manifiestan signos clínicos y, por tanto, se siguen movilizando y comercializando a lo largo del territorio nacional, convirtiéndose en verdaderos portadores del virus, $y$ al ser potencialmente infecciosos favorecen la permanencia del virus en campo. Pese a que son asintomáticos a la LBE, la infección con el virus los hace susceptibles a otras enfermedades, como Rinotraqueitis Infecciosa Bovina (7), Diarrea Viral Bovina, Leptospira, Mastitis y Metritis, entre otras (8), generando un importante impacto económico.

En Estados Unidos, las pérdidas en la industria lechera por cuenta de los animales asintomáticos son de 285 millones de dólares al año, con disminución hasta del $30 \%$ por infertilidad, abortos, bajos porcentajes de preñez (9), momificaciones, tasas de natalidad promedio de $53 \%$ y rápido descarte de los animales (10), y en Colombia, las pérdidas se calculan en 518.000 millones de pesos anuales (11).

El manejo proporcionado a los animales de producción puede intervenir en los mecanismos de transmisión del virus, en la respuesta inmune y en el ciclo viral en las células hospederas $(10,12)$. Para explicar estos eventos es necesario recurrir a las diferentes técnicas que pueden aportar información; por un lado están las técnicas serológicas, como el test de ELISA y el test de Inmunodifusión en gel de agar (IDGA), que se basan en la detec- ción de anticuerpos contra el virus y cuyo resultado depende de la capacidad del sistema inmune de los animales para producir anticuerpos contra el VLB, pero éstos puede variar en los periodos periparturientos (13) o cuando se utilizan suplementos forrajeros (14). Por otro lado, existen las pruebas moleculares, como la prueba de Reacción en Cadena de la Polimerasa (PCR), que amplifican fragmentos de los genes constitutivos del VLB -el gag, el pol y el env- $(15,8,16)$; la PCR tiene diferentes modalidades, como PCR convencional (15), PCR anidada (16) y PCR en Tiempo Real $(13,17)$, cuyo resultado no depende de la respuesta inmunológica de los animales, sino de la carga viral. Por lo anterior, el objetivo del presente trabajo fue detectar el VLB en fase proviral (insertado en el genoma bovino), amplificando un segmento del gen gag del VLB, mediante una prueba convencional de PCR, y evaluar si existe relación entre la presencia del virus en los animales, la ubicación geográfica y el tipo de explotación bovina, a fin de aportar conocimiento científico a la epidemiología molecular de la LBE en Colombia.

\section{Materiales y métodos}

\section{A. Tipo de estudio}

Descriptivo correlacional. Los animales muestreados, predominantemente de las razas Holstein y Cebú, con diferentes cruces, se definieron por conglomerados de región, generándose cuatro zonas; Centro (Cundinamarca y Boyacá), Norte (Santanderes), Oriente (Meta) y Sur (Huila y Tolima), y en función del tipo de explotación ganadera, los conglomerados fueron: carne (C), doble propósito (DP) y leche (L).

\section{B. Tamaño de muestra}

El tamaño de la muestra se calculó con base en el número de cabezas de ganado a nivel nacional reportado por el DANE (18), correspondiente a 25.000.000 de cabezas, considerando un nivel de confianza del $95 \%$, error de estimación del $6.5 \%$ y prevalencia de LBE en Colombia del $30 \%$ (2). Se muestrearon 230 animales sin signos paraclínicos evidentes, ubicados en las diferentes zonas establecidas (73 en la zona Centro, 39 en la zona Sur, 
49 en la zona Norte y 69 en la zona Oriente), a partir de un muestreo que fue diseñado por conveniencia, y que estuvo conformado por 73 animales destinados a la producción de leche (L), 90 a la producción de carne (C) y 67 al doble propósito (DP).

\section{Toma de muestras}

Las muestras de sangre fueron recolectadas entre enero y marzo de 2014, mediante venopunción en la vena caudal, para lo cual se tuvieron en cuenta los criterios bioéticos para el manejo de animales. Las muestras para las pruebas de ELISA fueron depositadas en tubos tapa marfil con gel separador (Vacutainer $\mathrm{BD}^{\circledR}$ ), y para las pruebas moleculares, en tubos tapa morada con anticoagulante EDTA (Vacutainer $\mathrm{BD}^{\circ}$ ). Los tubos fueron transportados conservando la cadena de frío hasta su llegada al Laboratorio de Biología Molecular. Los sueros fueron recolectados y almacenados a $-20{ }^{\circ} \mathrm{C}$ hasta su uso, y las muestras de sangre total fueron utilizadas para la extracción de ADN genómico bovino $y$, posteriormente, para las pruebas de PCR.

\section{Pruebas moleculares}

El ADN genómico bovino fue extraído por el método de extracción de Salting Out (19). La cantidad del material genético fue cuantificado por fluorometría en un equipo Qubit Invitrogen ${ }^{\oplus}$. Para descartar la presencia de inhibidores del PCR en el material genético extraído, se incluyó como control interno de la prueba la amplificación de un segmento de 400 pb del gen constitutivo bovino RPL-19, que codifica para una proteína ribosomal bovina (L-19). Los oligonucleótidos utilizados (F: 5'-3': GAAATCGCCAATGCCAAC y R: 5' -3 ': GAGCCTTGTCTGCCTTCA), las condiciones de la reacción y el programa del termociclador (MyCycler de $\mathrm{BioRad}^{\circ}$ ) fueron ajustados según lo reportado en la literatura (20). Posteriormente, se realizó la prueba de PCR para la amplificación de un segmento génico altamente conservado del gen gag del VLB, que codifica para la proteína P24 de la cápside viral. Los oligonucleótidos utilizados fueron descritos por DuSantos et al (15). Las condiciones de la reacción fueron: $1 \mathrm{X}$ de Buffer PCR (Invitrogen $\left.{ }^{\oplus}\right), 50 \mathrm{mM}$ de $\mathrm{MgCl}_{2}$ (Invitrogen ${ }^{\circ}$ ),
20 mM de Dntps (Invitrogen $\left.{ }^{\circ}\right), 10$ mM de PF y 10 mM de PR (Invitrogen $\left.{ }^{\circledR}\right), 1 \mathrm{U}$ de Taq Platinum (Invitrogen $\left.{ }^{\oplus}\right), 100 \mathrm{ng} / \mathrm{ml}$ de ADN bovino y se completó con agua HPLC hasta obtener un volumen final de $25 \mathrm{ml}$. Se utilizó un termociclador (MyCycler de BioRad ${ }^{\circ}$ ), con el siguiente programa: $95^{\circ} \mathrm{C}$ durante 30 segundos, $57{ }^{\circ} \mathrm{C}$ durante 30 segundos y $72{ }^{\circ} \mathrm{C}$ durante 60 segundos por 40 ciclos. En todos los ensayos se incluyó un control positivo y un control negativo; el control positivo utilizado fue un ADN proviral del VLB cepa americana cultivada en células de riñón de cordero, donado por el Departamento de Biotecnología del National Veterinary Research Institute (Laboratorio de referencia para la Leucosis Bovina de la OIE-Polonia), y como control negativo se utilizó agua grado biología molecular, en vez de ADN.

Por el tamaño del producto amplificado, fue visualizado en geles de agarosa al $3 \%$, y el corrido electroforético fue comparado con un marcador de longitud de 100-1000 Kb invitrogen ${ }^{\circledR}$. La reacción positiva se interpretó como un única señal de 380 $\mathrm{pb}$, correspondiente a un segmento del gen gag del VLB.

\section{E. Secuenciación}

Solo el fragmento de mayor concentración obtenido por PCR de una de las muestras, fue secuenciado en ambos sentidos en el Instituto Macrogen Inc-Korea ${ }^{\circledR}$. Las secuencias, fueron procesadas con FinchTV ${ }^{\oplus}$ y editadas con CLC Sequence viwer ${ }^{\oplus}$, y el análisis de identidad se realizó con el programa BLAST $^{\oplus}$.

\section{F. Validación de la prueba de PCR para VLB}

De las 230 muestras recolectadas, 52 presentaron sueros hemolisados y, por ende, fueron descartadas para esta prueba, ya que la hemolisis puede afectar el resultado del ELISA. En consecuencia, solo a 178 de las muestras se les realizó, además de la prueba molecular, la prueba serológica de ELISA (Gold Standart para LBE), con el fin de comparar los resultados arrojados por ambos ensayos y obtener el índice de concordancia (Kappa). La prueba de ELISA fue realizada en el Instituto Colombiano Agropecuario (ICA), en Bogotá, por ser 
el laboratorio de referencia para la LBE en Colombia.

\section{G. Métodos estadísticos y análisis de datos}

Para estimar la similitud entre la prueba molecular (PCR) y los conglomerados (región y tipo de producción), se utilizó la prueba exacta Ji-cuadrado, a partir del comando CrossTable de la librería gmodels (21) del lenguaje de programación R. Posteriormente, se calculó el índice Kappa, con el fin de validar la prueba molecular frente a la prueba de ELISA (Gold Standart para LBE).

\section{Resultados y discusión}

Del total de 230 animales muestreados, el $22.6 \%$ estaban infectados con el virus, a pesar de que nin- guno de ellos presentó sospecha de enfermedad o aparente reducción en los niveles de producción, según los registros sanitarios de la finca, por lo cual fueron considerados aparentemente sanos (pero no se realizaron exámenes paraclínicos). Al discriminar por ubicación, en la zona Centro se detectó el mayor número de animales con el virus (50.7 \%), seguida por la zona Oriente $(13 \%)$, la Norte $(8.2$ $\%$ ) y, finalmente, la Sur (5.2 \%), (Tabla I). Estos resultados son similares a los de un estudio molecular realizado en ganado criollo colombiano, donde el VLB se encontró en el $50 \%$ de los animales en la zona Centro y el $13 \%$ en la zona Oriente, pero difiere de lo encontrado en la zona Norte y Sur Occidente, con el $25 \%$ y $33 \%$, respectivamente (16), posiblemente debido al tipo razas bovinas evaluadas.

Tabla I. Distribución de resultados asociados a la detección molecular del VLB, con respecto a la región.

\begin{tabular}{|c|c|c|c|c|}
\hline \multirow{2}{*}{ Región } & \multicolumn{2}{|c|}{ Resultado PCR } & \multirow{2}{*}{$\begin{array}{c}\text { Total } \\
\text { Bovinos }\end{array}$} & \multirow{2}{*}{$\begin{array}{l}\text { Infectados } \\
(\%)\end{array}$} \\
\hline & Negativo & Positivo & & \\
\hline Centro & 36 & 37 & 73 & 50.7 \\
\hline Norte & 45 & 4 & 49 & 8.2 \\
\hline Oriente & 60 & 9 & 69 & 13.0 \\
\hline Sur & 37 & 2 & 39 & 5.1 \\
\hline Total & 178 & 52 & 230 & 22.6 \\
\hline
\end{tabular}

Si bien es cierto que las pruebas moleculares y las inmunológicas detectan analitos diferentes, en este caso se consideró importante comparar los resultados obtenidos con los datos serológicos reportados en la literatura, a fin de analizar la información que aporta cada prueba a la epidemiología de la enfermedad, encontrando alta correlación con el 45.8 $\%$ de la prevalencia serológica de la zona Centro, en animales de la Sabana de Bogotá, Valle de Ubaté y Chiquinquirá, utilizando la prueba AGID (7), y con el $3.9 \%$ al $14.64 \%$ de la seroprevalencia en la región Nororiental (16), frente al $8.2 \%$ y $13 \%$, respectivamente, con la prueba molecular (Tabla I). La menor correlación se detectó en el conglomerado Sur, donde las cifras de seropositividad son del $19 \%$ al $25 \%(3,4)$, en contraste con el 5.2 $\%$ detectado con la PCR.
La prueba de Ji cuadrado por conglomerado región evidenció relación entre la presencia del virus y la ubicación geográfica de los animales $\left(p \leq 1.21 \times 10^{-10}\right)$; por lo tanto, estos resultados sugieren que en próximos estudios es necesario discriminar los factores ambientales para detectar aqueIlos que pueden favorecer la dinámica viral en la región, importante a la hora de establecer programas de control y prevención de la LBE.

Con respecto a la presencia molecular del VLB por tipo de producción, los resultados se observan en la Tabla II. 
Tabla II. Distribución de resultados asociados a la detección molecular relacionados con respecto al tipo de producción.

\begin{tabular}{|c|c|c|c|c|}
\hline \multirow{2}{*}{$\begin{array}{l}\text { Tipo de produc- } \\
\text { ción }\end{array}$} & \multicolumn{2}{|c|}{ Resultado PCR } & \multirow{2}{*}{$\begin{array}{l}\text { Total bovi- } \\
\quad \text { nos }\end{array}$} & \multirow{2}{*}{$\begin{array}{c}\text { Infectados } \\
(\%)\end{array}$} \\
\hline & Negativo & Positivo & & \\
\hline Carne & 85 & 5 & 90 & 5.6 \\
\hline Doble Propósito & 57 & 10 & 67 & 14.9 \\
\hline Leche & 36 & 37 & 73 & 50.7 \\
\hline Total & 178 & 52 & 230 & 22.6 \\
\hline
\end{tabular}

El porcentaje más alto de detección del VLB fue en el conglomerado lechero (50.7\%), (Tabla II); resultado esperado, dado que los estudios han indicado que el ganado de leche es el más susceptible a la $\mathrm{LBE}$, con el $77.83 \%$, según registros en animales de las razas Holstein y Jersey en el Valle del Cauca (3), el $44 \%$ en ganado Holstein en el departamento de Antioquia (22) y el $83 \%$ de la misma raza a nivel nacional, utilizando pruebas moleculares (16). Estos datos revelan la alta presencia del virus en hatos destinados a la producción de leche, debido a que las prácticas de manejo zootécnico en estas razas facilita la transmisión entre animales clínicamente sanos, tales como la alta manipulación por técnicos en el ordeño, incremento en las palpaciones y uso para varios bovinos de agujas, guantes y demás elementos contaminados con sangre; además, la densidad entre animales favorece la propagación del virus por moscas e insectos hematófagos (23). Todo esto genera un efecto negativo en los parámetros reproductivos, afectando no solo la producción de leche, sino también el sostenimiento en las pequeñas ganaderías (24).

En el presente estudio se detectó el VLB en el 15 $\%$ del conglomerado de doble propósito (DP) (Tabla II), dato superior a lo reportado en un estudio seroepidemiológico a bovinos de cruce de razas Cebú, Simbra, Jerhol y Simental que mostró una prevalencia de $1.5 \%$ (25). El evidente incremento en la presencia del virus en el ganado de doble propósito presentado puede estar relacionado con el cruce con razas lecheras y el alto grado de manipulación, similar al ganado de leche, que, como ya se mencionó, facilita la transmisión horizontal y vertical del virus $y$, por ende, la permanencia del VLB en las fincas, mostrando claramente una necesidad de establecer estrategias de control en el ganado de doble propósito para impedir la transferencia del virus entre cruces de razas.

En cuanto al conglomerado carne $(\mathrm{C})$, la detección del VLB fue de $5.56 \%$ (Tabla II), comparativamente inferior con un estudio serológico realizado en ganado destinado para la producción de carne en la región de Yopal-Casanare, donde hallaron seroprevalencia del $15 \%$ (6). Para interpretar esta diferencia en el ganado de carne, se sugiere tener en cuenta factores como la edad de los animales, pues un estudio de LBE en ganado de carne en los Estado Unidos mostró una seroprevalencia de entre $1.2 \%$ y $10.3 \%$, indicando que el incremento de las cifras puede ser del $1 \%$ por año en relación con la edad de los animales (10), lo cual supone que las cifras moleculares del VLB pueden también incrementarse si se muestrean animales mayores. La presencia del VLB en el ganado de carne trae como consecuencia pérdidas económicas relacionadas con el tratamiento de enfermedades secundarias, inmunosupresión, decomiso de piezas en matadero (26) y disminución en el pie de cría, pero, sobre todo, afecta la exportación de ganado, ya sea en pie o en canal, pues es requisito indispensable para la comercialización que deben estar libres de LBE.

El Ji cuadrado por conglomerado de tipo de producción evidenció que existe relación $\left(p<1.32 \times 10^{-11}\right)$ entre la presencia del virus y el tipo de producción de los animales. En función de lo anterior, se puede inferir que las estrategias de control y prevención deben empezar con el uso de pruebas directas de detección del VLB y ajustarse al tipo de explotación bovina, teniendo en cuenta la edad de los animales, el tipo de pasturas, el manejo zootécnico y las condiciones propias de cada región, 
es decir, deben ser diseñadas para cada finca con programas de manejo y vigilancia particular (13).

Con el fin de validar la prueba molecular de PCR para la detección del VLB en animales de campo, utilizada en este estudio, fue necesario comparar sus resultados con los del test de ELISA (como técnica de referencia para LBE en Colombia). Los resultados se muestran en la Tabla III.

Tabla III. Prueba PCR vs. ELISA.

\begin{tabular}{cccc}
\hline & PCR $^{-}$ & PCR $^{+}$ & TOTAL ELISA \\
\hline ELISA $^{-}$ & 124 & 3 & 127 \\
ELISA $^{+}$ & 8 & 43 & 51 \\
TOTAL PCR $^{+}$ & 132 & 46 & 178 \\
\hline
\end{tabular}

Teniendo en cuenta que el test de ELISA es la prueba de referencia para LBE en Colombia, 178 animales fueron clasificados con esta prueba como positivos y negativos para LBE (127 reportados como negativos y 51 como positivos).

Al comparar los resultados de la PCR con los de ELISA se obtiene una sensibilidad del $84.3 \%$ (43/51) y una especificidad del $97.6 \%$ (124/127). El índice de concordancia Kappa entre las pruebas ELISA y PCR fue del 0.8442, que corresponde con una concordancia categorizada como Excelente $(k>0.8)(27)$; de otra parte, la sensibilidad de la prueba de PCR utilizada en este estudio supera los índices de la prueba molecular utilizada en otras investigaciones en ganado Holstein en Colombia, donde con 26 muestras totales reportan una sensibilidad del $52 \%$ (22).

Para verificar que el fragmento amplificado (380 pb) con la prueba de PCR, correspondía al gen gag del VLB y no a otro virus o gen bovino, el amplificado de una de las muestras fue secuenciado y comparado con secuencias registradas en el GenBank, encontrándose identidad de entre el $93 \%$ y el 99 \% con 21 secuencias del VLB (EF600696, K02120, FJ 009180, AY277948, FJ009179, FJ914764, FJ009183, EF190192, AF257515, AF033818,
M10987, AY589727, FJ009184, GQ491118, GQ491119, GQ491116, GQ491115, FJ009182, D00647, GQ491117, FJ009181).

De las 178 muestras procesadas por la prueba de PCR y ELISA, 11 (6.2\%) no fueron concordantes y seis pertenecían al conglomerado de leche (tres, considerados falsos positivos, y tres, falsos negativos), cuatro al conglomerado de doble propósito (cuatro falsamente negativas) y una al conglomerado de carne (falsamente negativa). Estas inconsistencias pueden estar asociadas a factores propios del tipo de explotación, del ciclo viral, del sistema inmune de los animales o, simplemente, a las características propias de cada técnica; sin embargo, precisar lo anterior requiere más estudios. Los resultados de este trabajo indican que la detección molecular del VLB y los hallazgos seroepidemiológicos pueden apoyar la evidencia científica de la dinámica del virus en el campo colombiano, pero es evidente que una prueba de PCR óptimamente estandarizada y validada permite detectar el virus de manera temprana, identificar animales potencialmente infecciosos y bloquear el ciclo de transmisión, teniendo en cuenta las condiciones de manejo de cada tipo de producción bovina.

\section{Conclusiones}

Los resultados de este trabajo permiten concluir que la presencia del VLB en los animales está significativamente relacionada con el tipo de producción bovina; el manejo de las explotaciones lecheras y de doble propósito generan más factores de riesgo, por lo tanto, se debe tener una vigilancia exhaustiva, con registros individuales y poblacionales, y contar con pruebas paraclínicas que permitan establecer el verdadero diagnóstico de la finca.

La alta especificidad de la prueba molecular, encontrada en este trabajo, es útil en animales de regiones no endémicas y en explotaciones bovinas de carne y doble propósito, debido a su capacidad para descartar la presencia del virus en los animales.

La presencia del VLB en los bovinos está significativamente relacionada con la ubicación geográfica 
de estos, por lo tanto, se debe contar con una estrategia de control inter regiones de la LBE a la hora de movilizar animales para la comercialización.

\section{Agradecimientos}

Al Dr. Jacek Kuzmak, por la donación del VLBFLKV (control positivo) para las pruebas moleculares; al Dr. Aldemar Zuñiga y a su equipo, por la toma de muestras, y a la Universidad de Ciencias Aplicadas y Ambientales (UDCA), por la financiación de esta investigación.

\section{Referencias}

(1) Hernández D, Muñoz J, Álvarez L. Asociación del Locus BOLA-DRB3.2 con el Virus de la Leucosis Bovina en el Ganado Criollo Colombiano. Rev. Colombiana Cien Anim. 2014; 6 (2): 319-326.

(2) Gallego M, Manejo del problema reproductivo en ganado de leche. Bogotá: UDCA. 2009.

(3) Cadavid G. Impacto del virus de la leucosis bovina en la produccion de leche. Tesis de Maestría. Facultad de Ciencias Agropecuarias. Universidad Nacional de Colombia Sede Palmira. 2012.

(4) Sandoval R, Delgado A, Ruiz L, Ramos O. Determinación de la seroprevalencia del virus de la Leucemia Bovina en un establo lechero de Lima, Perú. Revista de Investigaciones Veterinarias del Perú. 2015; 26: 152158. DOI: http://dx.doi.org/10.15381/rivep. v26i1.10919.

(5) Carrero JL, Arévalo F, Tarazona A, Cepeda BM. Prevalencia de la seropositividad de la leucosis bovina mediante la técnica de ELISA indirecta en hatos lecheros situados en la Mesa de los Santos, Santander. SPEI Domus. 2009; 5(11): 6-11.

(6) Bautista NA, Nova $Y$, Pulido-Medellín $M$, Andrade-Becerra R. Determinación serológica de leucosis bovina enzoótica en novillas de levante y vacas adultas de la vere- da Morichal, Yopal, Casanare. Rev. Cien. Agri., 2013; 10: 31-37. DOI: http://dx.doi. org/10.19053/01228420.2832.

(7) Alfonso R, Almansa JE, Barrera J del C. Prevalencia serológica y evaluación de los factores de riesgo de leucosis bovina enzoótica en la Sabana de Bogotá y los Valles de Ubaté y de Chiquinquirá, Colombia. Rev. Sci. Tech. Off. int. Epiz. 1998; 17(3): 723-732.

(8) Heenemann K, Lapp S, Teifke JP, Fichtner D, Mettenleiter TC, Vahlenkamp TW. Development of a Bovine leukemia virus polymerase gene-based real-time polymerase chain reaction and comparison with an envelope. Journal of Veterinary Diagnostic Investigation. 2012; 24: 649-55. DOI: http://dx.doi. org/10.1177/1040638712447524.

(9) Algorta A. Leucosis Bovina Enzoótica en un campo de recría de ganado lechero en el sur del Uruguay. Tesis de Doctorado. Facultad de Veterinaria. Universidad de la República. Montevideo-Uruguay, 2014.

(10) Barlett PC, Sordillo LM, Byrem TM, Norby B, Grooms DL, Swenson CL, Zalucha J, Erskine RJ. Options for the control of bovine leukemia virus in dairy cattle. JAVMA. 2014; 244 (8): 914-922. DOI: http://dx.doi.org/10.2460/javma.244.8.914.

(11) FEDEGAN. Federación Colombiana de Ganaderos. Situación en Colombia de enfermedades bovinas no sujetas a control oficial. 2011.

(12) Kobayashi S, Tsutsui T, Yamanoto T, Hayama Y, Kameyama K, Konishi, Murakami K. Risk factor associated with within-herd transmisión of bovine leucemia virus on Dairy farms in Japan. BMC veterinary research. 2010; 6: 1-6. DOI: http://dx.doi.org/10.1186/1746-6148-61.

(13) Rama G. Desarrollo y análisis comparativo de una nueva herramienta para el diagnóstico de la Leucosis Bovina Enzoótica, Impacto del descenso de AC anti-VLB circulantes en el 
periparto para el diagnóstico serológico. Tesis de Maestría en Biotecnología. Laboratorio de Técnicas Nucleares. Facultad de Veterinaria, Universidad de la República, Uruguay. 2013.

(14) Tirziu E, Cumpanasoiu C, Nichita I, Reman G, Sonea C, Seres M. Performance assessment of three tests applied in enzootic bovine leukosis diagnosis. Romanian Biotechnological Letters. 2014; 19(5): 9666-9677.

(15) Dus Santos M, Trono K, Larger I, Wigdorovitz A. Development of PCR to diagnose BLV genome in frozen semen samples. Veterinary Microbiology. 2007; 119: 10-18. DOI: http:// dx.doi.org/10.1016/j.vetmic.2006.08.030.

(16) Hernández-Herrera DY, Posso-Terranova AM, Benavides JA, Muñoz-Flórez JE, Giovambattista G, Álvarez-Franco L. Detección del virus de la leucosis bovina en ganado criollo colombiano mediante PCR-anidado. Acta Agronómica. 2011; 60: 312-318.

(17) Rola-Luszcaz $M$, Finnegan C, Olech $M$, Choudhury B, Kuzmak J. Development of an improved real time PCR for detection of bovine leukaemia provirus nucleica cid and its use in the clarification of inconclusive serological test results. Journal of Virological Methods. 2013; 189: 258-264. DOI: http://dx.doi.org/10.1016/j.jviromet.2013.02.014.

(18) DANE, Oficina de Prensa. Información estadística. Inventario ganado vacuno. 2012. DANE- ENA 2012. Disponible: http:// www.dane.gov.co/files/investigaciones/ agropecuario/enda/ena/cp_ena_2012.pdf.

(19) Meza G, Ulloa JC, Uribe AM, Gutiérrez MF. Técnica no convencional de extracción de ADN a partir de tejido embebido en parafina para uso en la PCR. Rev. UDCA Act. \& Div. Cient. 2013. 16(1): 35-41.

(20) Giotto L, Bricarello PA, Talamini, AF, Coutinho L. Quantification of bovine cytokine gene expression using real-time RT-PCR methology. Genetics and Molecular Biology. 2007; 30(3):
575-579. DOI: http://dx.doi.org/10.1590/ S1415-47572007000400012.

(21) Warnes GR, Bolker B, Lumley T, Johnson RC. Contributions from Randall C. Johnson are Copyright SAIC-Frederick, Inc. Funded by the Intramural Research Program, of the $\mathrm{NIH}$, National Cancer Institute and Center for Cancer Research under $\mathrm{NCl}$ Contract NO1CO-12400. (2015). gmodels: Various R Programming Tools for Model Fitting. $R$ package version 2.16.2. https://CRAN.R-project.org/ package $=$ gmodels .

(22) Úsuga C, Echeverri J, López-Herrera A. Diagnóstico Molecular del Virus de la Leucosis Bovina en una población de vacas Holstein, Colombia. Arc. Zootec. 2015; 64(248): 383388.

(23) Evermann J. Cause for Concern: Bovine Leukemia Virus. Washington State University Extension \& WSU College of Veterinary Medicine. 2014. June: 1-5.

(24) Úsuga-Monroy C, Echeverri JJ, López- Herrera A. Asociación entre la infección por virus de la Leucosis Bovina y parámetros reproductivos en ganado Holstein colombiano. AICA. 2015; 6: 419-423.

(25) Betancur C, Rodas J. Seroprevalencia del virus de la leucosis viral bovina en animales con trastornos reproductivos en Montería. Rev. MVZ Códoba. 2008; 13(1): 1197-1204.

(26) Nava Z. Obando C, Bracamonte M, Sousa A, Hidalgo M. Evaluación de la Eficacia de la Prueba de Inmunodifusión en gel de Agar para la detección de anticuerpos contra el virus de la leucosis bovina. Revista Facultad de Ciencias Veterinarias. 2012; 53(1): 21-27.

(27) Cerda J, Villarroel L. Evaluación de la concordancia inter-observador en investigación pediátrica: Coeficiente Kappa. Rev Chil Pediatr. 2008; 79 (1): 54-58. DOI: http://dx.doi. org/10.4067/S0370-41062008000100008. 